OPEN ACCESS

Edited by:

Linxin Li,

University of Oxford, United Kingdom

Reviewed by:

Mohamed Al-Khaled,

University of Lübeck, Germany

Xiping $X u$,

Southern Medical University, China

*Correspondence:

Wenli Hu

wenlihu3366@126.com

Specialty section:

This article was submitted to

Stroke,

a section of the journal

Frontiers in Neurology

Received: 15 March 2019

Accepted: 10 July 2019

Published: 13 August 2019

Citation:

Yuan J, Jia Z, Song Y and Hu W (2019) External Validation of the Diagnosis of TIA (DOT) Score for Identification of TIA in a Chinese

Population. Front. Neurol. 10:796. doi: 10.3389/fneur.2019.00796

\section{External Validation of the Diagnosis of TIA (DOT) Score for Identification of TIA in a Chinese Population}

\author{
Junliang Yuan ${ }^{1}$, Zejin $\mathrm{Jia}^{1}$, Yangguang Song ${ }^{2}$ and Wenli $\mathrm{Hu}^{1 *}$ \\ ${ }^{1}$ Department of Neurology, Beijing Chaoyang Hospital, Capital Medical University, Beijing, China, ${ }^{2}$ Department of Pathology, \\ Beijing Chaoyang Hospital, Capital Medical University, Beijing, China
}

Background: Recently, the [diagnosis of transient ischemic attack (TIA), DOT] score has been recognized to be a new tool for non-specialists to diagnose TIA more accurately with the sensitivity and specificity being 89 and 76\%, respectively. However, the DOT score has not yet been validated externally in patients with TIA in China.

Methods: We retrospectively enrolled 500 consecutive patients with transient neurological symptoms, who were admitted to the Department of Neurology, Beijing Chaoyang Hospital and underwent magnetic resonance imaging (MRI) between Jan 2016 and Dec 2018. Patients with transient neurological symptoms were divided into two subgroups: TIA mimic group $(N=140,28 \%)$ and definite cerebrovascular events group including tissue-based TIA (DWI negative, $N=252,50.4 \%$ ) and minor stroke (DWI positive, $N=108,21.6 \%)$. The demographic data, clinical characteristics, laboratory findings, and scores of Dawson and DOT were compared between the two groups.

Results: A total of 500 patients with transient neurological symptoms (mean age, 61.1 $\pm 12.8)$ were enrolled and $70 \%(N=350)$ were male. Comparing with TIA mimic groups, patients with cerebrovascular events group were more likely to have higher diastolic blood pressure, uric acid and homocysteine, more motor weakness and speech abnormalities, and also scored higher using the Dawson and DOT. The area under the curve (AUC) was 0.728 for DOT, with a sensitivity of $70.3 \%$ and specificity of $62.9 \%$, respectively.

Conclusion: In patients with transient neurological symptoms, our findings showed that the DOT score had relatively good calibration and discrimination to identify of TIA in a Chinese Population. As a novel tool of TIA identification, further validations are needed in multiple centers with larger samples in China.

Keywords: transient ischemic attack, diagnosis of TIA score, Dawson score, ischemic stroke, diffusion weighted imaging

\section{INTRODUCTION}

Stroke is the second leading cause of death worldwide with an annual mortality rate of about 5.5 million $(1,2)$, and the first in China (3). Transient ischemic attack (TIA) is a transient episode of local neurologic dysfunction and it is a prodromal stage of stroke especially in the first few days (4). However, the precise estimate of TIA is difficult mainly due to the varying criteria utilized to identify a TIA. TIA was classically defined as a focal cerebral ischemic event with symptoms lasting $<24 \mathrm{~h}$. Due to the rapid development of neuroimaging, up to one-third of patients with TIA may 
have radiological evidence of acute infarction $(5,6)$. The frequency of positive diffusion-weighted imaging (DWI) findings varied from 9 to $67 \%$ among different cohorts of patients with TIA (7-9). Therefore, the definition of TIA is changing from "time-based TIA" to "tissue-based TIA," which is "a transient episode of neurological dysfunction caused by focal brain, spinal cord, or retinal ischemia, without acute infarction" (10). Changing the definition of TIA could lead to a landmark to evaluate the progress of stroke.

It has been reported $20 \%$ of stroke could be preceded by an episode of TIA. TIA represents really a major warning, and patients with TIA have the highest risk of early, recurrent stroke or other cardiovascular events (11-13). TIA is poorly managed in many countries, thus, it is of great significance to focus on the early differentiation TIA from minor stroke or common TIA mimics (14). As for diagnostic algorithms for TIA, as far as we know, there have been only two tools previously developed. The first clinical scoring tool was Dawson score (Table 1), however, it is less accurate in primary care than in specialist care (16), and lack of retinal and posterior circulation cerebrovascular events assessment (15). The second tool was the Diagnosis of TIA (DOT) score (Table 2), which was considered to be a new tool for non-specialists to make the diagnosis of TIA with greater accuracy with the sensitivity and specificity were 89 and $76 \%$, respectively. The area under the curve (AUC) of DOT score was 0.89 , however, the Dawson score was 0.77 (17). However, this new tool of DOT has not yet been externally validated in other populations before widely utilized. Thus, the aim of the present study was aimed to investigate the validation of DOT score as a new clinical diagnostic tool of TIA in patients with transient neurological symptoms.

\section{MATERIALS AND METHODS}

\section{Subjects}

Our study was a retrospective, observational study in the Department of Neurology, Beijing Chaoyang Hospital, Capital Medical University. We retrospectively enrolled 500 patients with

TABLE 1 | TIA scoring system (Dawson score) (15).

\begin{tabular}{lccc}
\hline Variable & Score if yes & Score if no & Std. error $(\boldsymbol{P}$-value $)$ \\
\hline History of stroke or TIA & 0.5 & 0 & $0.1\left(3.5 \times 10^{-7}\right)$ \\
Headache & 0 & 0.5 & $0.11\left(7.1 \times 10^{-5}\right)$ \\
Diplopia & 1.2 & 0 & $0.28\left(2.7 \times 10^{-6}\right)$ \\
Loss of consciousness/ & 0 & 1.1 & $0.21\left(1.9 \times 10^{-7}\right)$ \\
Pre-syncope & 0 & 1.6 & $0.43\left(1.4 \times 10^{-4}\right)$ \\
Seizure & 0 & 0 & $0.14\left(<110^{-10}\right)$ \\
$\begin{array}{l}\text { Speech abnormalities } \\
\text { Unilateral limb }\end{array}$ & 1.3 & 0 & $0.10\left(<1 \times 10^{-10}\right)$ \\
weakness & 1.7 & 0 & $0.15\left(9.5 \times 10^{-8}\right)$ \\
$\begin{array}{l}\text { Upper motor neuron } \\
\text { facial weakness }\end{array}$ & 0.6 & & $0.004\left(<1 \times 10^{-10}\right)$ \\
Age & Multiply by 0.04 &
\end{tabular}

All values reflect the regression coefficients seen and $P$-values refer to significance of each variable in the final model. Std. Error, Standard Error. To calculate the score, all values should be summed. If total score $>6.1$, classify as TIA. For "2:1 cost ratio," if total score $>5.4$, classify as TIA. transient neurological symptoms between Jan 2016 and Dec 2018 and they all underwent magnetic resonance imaging (MRI) scans. TIA is classically defined to be the presence of focal neurological symptoms due to a vascular etiology lasting $<24 \mathrm{~h}$, irrespective of imaging findings (18). Patients with transient neurological symptoms were divided into two subgroups: TIA mimic group, and cerebrovascular events group including tissue-based TIA (DWI negative) and minor stroke (DWI positive). The tissuebased definition of TIA was proposed to classify patients only if the symptoms fit the clinical syndrome and no acute ischemic lesion identified by DWI (10), whereas minor stroke was similar to the above but positive DWI. However, there are some patients with transient focal neurological symptoms which are not due to focal cerebral ischemia, thus, the patients with an underlying non-ischemic disorder were classified as TIA mimics (such as epileptic seizures, migraine) (19). Our work was approved by the Ethics Committee of Beijing Chaoyang Hospital, Capital Medical University. Written informed consent was obtained from all participants.

\section{Clinical Variables}

We retrospectively obtained the following clinical data: age, gender; vascular risk factors such as hypertension, diabetes mellitus, hyperlipidemia, stroke, coronary heart disease, atrial fibrillation, and current smoking. The laboratory blood tests were also obtained from medical records, including the counts of red blood cell, white blood cell, platelet, hemoglobin, fibrinogen, fasting blood glucose, hemoglobin A1c, glycated albumin, uric acid, homocysteine, total cholesterol, lowdensity lipoprotein, high-density lipoprotein, triglyceride, Creactive protein, albumin, pre-albumin, folic acid and 25hydroxy vitamin $\mathrm{D}$. The scores of Dawson and DOT were also calculated. The presenting symptoms of TIA included motor weakness, sensory disturbance, speech abnormalities (dysarthria or aphasia), loss of consciousness, ataxia, diplopia, and hemianopia. The durations of TIA were classified into three categories: $<10 \mathrm{~min}, 10-59 \mathrm{~min}$, or more than $1 \mathrm{~h}$. The time from symptom onset to MRI and the used medication were also documented.

\section{Statistical Analysis}

The data were described using the mean and standard deviation values for continuous variables, the median and interquartile range values for categorical variables, and absolute numbers and percentages for nominal and categorical variables, and we compared the groups using the nonparametric MannWhitney $U$-test. We performed a chi-square test between categorical variables and a $t$-test between continuous variables. The dependent variable was "definite cerebrovascular events," which included tissue-based TIA and minor stroke (17). The calibration of the models was tested by calibration plots and the Hosmer-Lemeshow statistic, and the discrimination was tested by Receiver Operating Characteristic (ROC) curves and AUC. We used the Statistical Package for Social Sciences (SPSS) version 16.0 (SPSS Inc., Chicago, IL, USA) for data analysis. A $P$-value $<0.05$ was considered statistically significant. 
TABLE 2 | The diagnosis of transient ischemic attack (DOT) score (17).

\begin{tabular}{|c|c|c|}
\hline Item & Input & Explanatory notes \\
\hline Age & & Enter age in years. \\
\hline History of hypertension & & Select if patient has a history of hypertension even if recently diagnosed. \\
\hline Atrial fibrillation (AF or PAF) & & Select if patient has known AF, PAF or atrial flutter or has just been found by you to be in AF. \\
\hline Dysphasia (disorder of language) & $\|$ & $\begin{array}{l}\text { Select ONLY if patient had word finding difficulties, jumbled speech or was unable to speak. Slurring } \\
\text { of speech (dysarthria) does NOT count as dysphasia. }\end{array}$ \\
\hline Unilateral facial weakness & $\|$ & $\begin{array}{l}\text { Select if patient had unilateral upper motor neuron (forehead sparing) facial weakness. If patient has } \\
\text { isolated facial weakness at present and it is a lower motor neuron weakness, consider Bells Palsy. }\end{array}$ \\
\hline Unilateral weakness of arm, leg or both & & $\begin{array}{l}\text { This must be GENUINE weakness. Tingling, numbness, heaviness, deadness or pain does NOT } \\
\text { count unless there was true weakness. Ask if it was difficult to move the limb or grip. }\end{array}$ \\
\hline Unilateral sensory loss & 凹 & $\begin{array}{l}\text { This must be genuine LOSS of sensation. Tingling, numbness or deadness does NOT count unless } \\
\text { patient is sure there was loss of pain, temperature or touch sensation. }\end{array}$ \\
\hline Visual loss in one eye & $\|$ & $\begin{array}{l}\text { Either partial or complete monocular blindness. Check if patient is sure it was one eye-did they } \\
\text { close each eye in turn? Transient loss can be due to a TIA affecting the eye. Persistent visual loss } \\
\text { can have a broader differential diagnosis and in all cases, an ophthalmology review is required. }\end{array}$ \\
\hline Visual loss in both eyes & & Applies to complete blindness affecting both eyes. \\
\hline Diplopia & ॥ & Double vision. Does NOT apply to non-specific blurring of vision. \\
\hline Homonymous hemianopia & $\Gamma$ & $\begin{array}{l}\text { Applies to visual loss in either the right or left visual field. Please do not mistake this for monocular } \\
\text { blindness or vice versa. }\end{array}$ \\
\hline Visual aura & 川 & $\begin{array}{l}\text { Applies to scintillations (flashing lights), fortification spectra (zig-zag lines) or spreading scotoma as } \\
\text { in a migraine type visual aura. }\end{array}$ \\
\hline Ataxia & & Applies to inco-ordination of the limbs or gait. \\
\hline Headache & 1 & Applies to any headache before, with or after the episode. \\
\hline Amnesia & 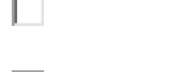 & $\begin{array}{l}\text { Does the patient remember the episode? Do not select if patient has dementia and is unlikely to } \\
\text { remember what happened. }\end{array}$ \\
\hline Loss of consciousness or near LOC & 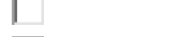 & This applies to loss of consciousness due to any reason or near LOC. \\
\hline Tingling and numbness & 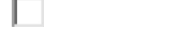 & This applies to tingling, numbness or pins and needles to any part of the body including face. \\
\hline Evaluate & Calculate DOTS & Reset \\
\hline
\end{tabular}

\section{RESULTS}

We enrolled a total of 500 patients with transient neurological symptoms, and the mean age was $61.1 \pm 12.8$ years, and $70 \%(N=350)$ were male. Among the patients with transient neurological symptoms, we found that TIA mimics $(N=140$, $28 \%$ ) and cerebrovascular events including tissue-based TIA $(N=252,50.4 \%)$ and minor stroke $(N=108,21.6 \%)$.

Table 3 showed the demographics, baseline clinical characteristics, vascular risk factors, the duration of TIA and the time from symptom onset to MRI. In cerebrovascular events group, the use of medication was shown: the aspirin (36.9\%), clopidogrel (19.4\%), dual antiplatelet therapy (42\%), and anticoagulation (1.7\%). The laboratory findings were presented in Table 4. We found there were significant differences in diastolic blood pressure, uric acid and homocysteine, the proportion of motor weakness and speech abnormalities, and the scores of Dawson and DOT between the two groups $(P<0.05)$.

As for the calibration and discrimination, predicted and observed diagnoses were plotted by the AUC with 95\% CI. Figure 1 showed the calibration plots (predicted vs. observed results), and the $P$-value was 0.541 for the Hosmer-Lemeshow test of goodness of fit. From Table 5 and Figure 2, we found the AUC $(95 \%$ CI) of the Dawson and DOT for predicting the cerebrovascular events were 0.681 (95\% CI, 0.629-0.732) and
0.728 (95\% CI, 0.680-0.776), respectively. The score of DOT showed a greater AUC, with sensitivity of $70.3 \%$ and specificity of $62.9 \%$, respectively. The optimal cut point for DOT score was 0.455 using the Youden Index.

\section{DISCUSSION}

In our present study, among patients with transient neurological symptoms, the patients with cerebrovascular events were more likely to be higher diastolic blood pressure, uric acid and homocysteine, more motor weakness and speech abnormalities, and higher scores of Dawson and DOT. DOT score showed relatively good calibration and discrimination to identify of TIA in a Chinese population.

TIA requires urgent investigation and treatment. The term "transient neurological symptoms" is used to describe a broad spectrum of symptoms following TIA or TIA mimics (20). Unilateral weakness and speech disturbances are the most common clinical manifestations of TIA, and our findings were in accordance with the prior studies $(21,22)$. It was reported unilateral weakness and speech disturbance were found in $\sim 31-$ $54 \%$ and $25-42 \%$ of TIA, respectively (5). There is no gold standard clinical tool used to diagnose TIA or stroke only based on symptomology, thus, accurate identification of TIA or stroke 
TABLE 3 | The baseline demographics, clinical characteristics between the two groups.

\begin{tabular}{|c|c|c|c|}
\hline Variables & $\begin{array}{c}\text { TIA } \\
\text { mimics (140) }\end{array}$ & $\begin{array}{l}\text { Cerebrovascular } \\
\text { events }(360)\end{array}$ & $P$ \\
\hline \multicolumn{4}{|l|}{ Demographics } \\
\hline Age(Y) & $60.1 \pm 12.0$ & $61.5 \pm 13.1$ & 0.273 \\
\hline Sex(Male, \%) & $90(64.3 \%)$ & $260(72.2 \%)$ & 0.082 \\
\hline $\begin{array}{l}\text { Systolic blood } \\
\text { pressure(mmHg) }\end{array}$ & $143.6 \pm 20.4$ & $146.9 \pm 21.2$ & 0.117 \\
\hline $\begin{array}{l}\text { Diastolic blood } \\
\text { pressure(mmHg) }\end{array}$ & $79.8 \pm 11.6$ & $83.5 \pm 13.6$ & $0.003^{*}$ \\
\hline \multicolumn{4}{|l|}{ Vascular risk factors } \\
\hline Hypertension & 78 (55.7\%) & 229 (63.6\%) & 0.103 \\
\hline Diabetes mellitus & $50(31.2 \%)$ & 110 (26.5\%) & 0.267 \\
\hline Coronary disease & $8(5.7 \%)$ & $28(7.8 \%)$ & 0.423 \\
\hline Prior stroke & 22 (15.7\%) & 71 (19.7\%) & 0.301 \\
\hline Hypercholesterolemia & 104 (74.3\%) & 255 (70.8\%) & 0.441 \\
\hline Atrial fibrillation & $2(1.4 \%)$ & $12(3.3 \%)$ & 0.246 \\
\hline $\begin{array}{l}\text { Peripheral arterial } \\
\text { disease }\end{array}$ & $5(3.6 \%)$ & $5(1.4 \%)$ & 0.118 \\
\hline Smoking & $59(42.1 \%)$ & $184(51.1 \%)$ & 0.072 \\
\hline \multicolumn{4}{|l|}{ Clinical features } \\
\hline Motor weakness & 48 (34.3\%) & $231(64.2 \%)$ & $0.001^{*}$ \\
\hline Sensory disturbance & $31(22.1 \%)$ & 105 (29.2\%) & 0.113 \\
\hline Speech abnormalities & $36(25.7 \%)$ & 145 (40.3\%) & $0.002^{*}$ \\
\hline Ataxia & $7(5.0 \%)$ & $19(5.3 \%)$ & 0.900 \\
\hline Diplopia & $9(6.4 \%)$ & $19(5.3 \%)$ & 0.615 \\
\hline Loss of consciousness & $16(11.4 \%)$ & 25 (6.9\%) & 0.101 \\
\hline Hemianopia & $2(1.4 \%)$ & $14(3.9 \%)$ & 0.160 \\
\hline Duration of TIA & & & 0.846 \\
\hline$<10 \min$ & $60(45.5 \%)$ & 150 (47.6\%) & \\
\hline 10-59 min & 50 (37.9\%) & 142 (40.3\%) & \\
\hline $1 \mathrm{~h}$ & $22(16.7 \%)$ & $60(17 \%)$ & \\
\hline $\begin{array}{l}\text { Time from symptom } \\
\text { onset to MRI, days }\end{array}$ & $5(3-11)$ & $6(4-13.75)$ & 0.224 \\
\hline
\end{tabular}

Data were presented as median with interquartile range in parentheses or number with the percentage in parentheses. ${ }^{*} P<0.05$.

TIA, transient ischemic attack; $M R I$, magnetic resonance imaging.

patients is quite difficult. It was reported up to $50-60 \%$ of TIA patients were diagnosed to be non-cerebrovascular mimics by non-specialists (23). Another data showed that up to $35 \%$ of referrals to TIA clinics were non-vascular mimics (24). Thus, it is especially crucial about the differential diagnosis of transient neurological symptoms from TIA or TIA mimics in clinical practice (e.g., migraine or seizure) $(20,25)$.

As a result, a TIA diagnostic tool to differentiate some TIA mimics from urgent TIA would be much valuable. To date, there have been only two tools for the early diagnosis of TIA. The clinical scoring system of Dawson was proved to facilitate to detect of TIA accurately. However, it has some limitations both on the utility only in primary care and not including posterior circulation cerebrovascular events (15). The second tool was the DOT score, which was recognized to be a new tool to make the diagnosis of TIA more accurate (17). However, this new tool of
TABLE 4 | The laboratory findings and the risk scores of TIA in all TIA patients.

\begin{tabular}{|c|c|c|c|}
\hline Variables & $\begin{array}{l}\text { TIA mimics } \\
\qquad(140)\end{array}$ & $\begin{array}{l}\text { Cerebrovascular } \\
\text { events }(360)\end{array}$ & $P$ \\
\hline White blood cell $\left(10^{9} / \mathrm{L}\right)$ & $7.1 \pm 20$ & $7.0 \pm 2.2$ & 0.636 \\
\hline Red blood cell (1012/L) & $4.5 \pm 0.7$ & $4.5 \pm 0.6$ & 0.999 \\
\hline Hemoglobin (g/L) & $141 \pm 14.7$ & $141 \pm 17.5$ & 0.989 \\
\hline Platelet $\left(10^{9} / \mathrm{L}\right)$ & $213.6 \pm 52.4$ & $215 \pm 59.6$ & 0.798 \\
\hline Albumin (g/L) & $41.9 \pm 7.4$ & $42.5 \pm 7.2$ & 0.363 \\
\hline Pre-albumin (g/L) & $0.3 \pm 0.7$ & $0.3 \pm 0.5$ & 0.285 \\
\hline $\begin{array}{l}\text { Total cholesterol } \\
(\mathrm{mmol} / \mathrm{L})\end{array}$ & $4.7 \pm 1.0$ & $4.6 \pm 1.0$ & 0.239 \\
\hline $\begin{array}{l}\text { High-density lipoprotein } \\
\text { (mmo//L) }\end{array}$ & $1.1 \pm 0.3$ & $1.1 \pm 0.4$ & 0.449 \\
\hline $\begin{array}{l}\text { Low-density lipoprotein } \\
\text { (mmo//L) }\end{array}$ & $2.8 \pm 0.8$ & $2.7 \pm 0.9$ & 0.07 \\
\hline Triglyceride (mmol/L) & $1.8 \pm 1.5$ & $2.0 \pm 2.0$ & 0.296 \\
\hline Uric acid ( $\mu \mathrm{mol} / \mathrm{L})$ & $312.2 \pm 89.1$ & $337.7 \pm 88$ & $0.004^{\star}$ \\
\hline Homocysteine ( $\mu \mathrm{mol} / \mathrm{L})$ & $15.1 \pm 7.0$ & $17.8 \pm 10.3$ & $0.007^{\star}$ \\
\hline Folic acid(ng/ml) & $6.7 \pm 5.1$ & $6.1 \pm 4.8$ & 0.251 \\
\hline $\begin{array}{l}\text { 25-hydroxy vitamin D } \\
\text { (ng/mL) }\end{array}$ & $14.5 \pm 4.8$ & $15.2 \pm 12.7$ & 0.752 \\
\hline $\begin{array}{l}\text { C-reactive protein } \\
\text { (mg/L) }\end{array}$ & $1.6(0.8 \sim 2.7)$ & $1.7(0.8 \sim 3.0)$ & 0.404 \\
\hline Fibrinogen (mg/dl) & $267.3 \pm 66.6$ & $272.9 \pm 78.7$ & 0.468 \\
\hline $\begin{array}{l}\text { Fasting blood glucose } \\
\text { (mmol/L) }\end{array}$ & $6.4 \pm 2.3$ & $6.8 \pm 3.3$ & 0.209 \\
\hline hemoglobin A1c (\%) & $6.3 \pm 1.1$ & $6.4 \pm 1.4$ & 0.880 \\
\hline Glycated albumin(\%) & $13.7 \pm 3.6$ & $15.1 \pm 4.1$ & 0.398 \\
\hline Dawson score & $6.5 \pm 1.3$ & $7.3 \pm 1.4$ & $0.001^{\star}$ \\
\hline DOT score & $\begin{array}{c}-0.04 \\
(-2.1 \sim 0.92)\end{array}$ & $\begin{array}{c}1.25 \\
(0.31 \sim 3.47)\end{array}$ & $0.001^{*}$ \\
\hline
\end{tabular}

Values represent number (percent) for categorical variables and mean $\pm S D$ or median (interquartile range) for continuous variables. ${ }^{*} P<0.05$.

DOT, diagnosis of TIA.

DOT has not yet been externally validated in other populations out of the United Kingdom. Our findings indicated that DOT score performed relatively good calibration and discrimination, with a sensitivity of $70.3 \%$ and specificity of $62.9 \%$. We also found there was greater AUC of DOT (0.728) compared with Dawson (0.681). According to Dutta D study in 2016, the AUC for DOT was 0.89 and Dawson score was 0.77 . Our findings were consistent with Dutta D study (17).

Our study also had some limitations. First, this study was designed as a retrospective study from a single center, which is one potential limitation. Studies with larger numbers from multiple centers in China are needed to confirm our findings. Second, we did not perform follow-ups to assess the risk factors of the recurrence of TIA or stroke, which may be of great importance for the assessment and management of TIA. Third, we did not perform the etiological classification of stroke/TIA, according to the Trial of Org 10172 in Acute Stroke Treatment. Fourth, we did not find blood or imaging biomarkers available to reliably distinguish TIA from TIA mimics (22).

Despite these limitations, as far as we know, the present study is the largest ever-reported study to identify the clinical 


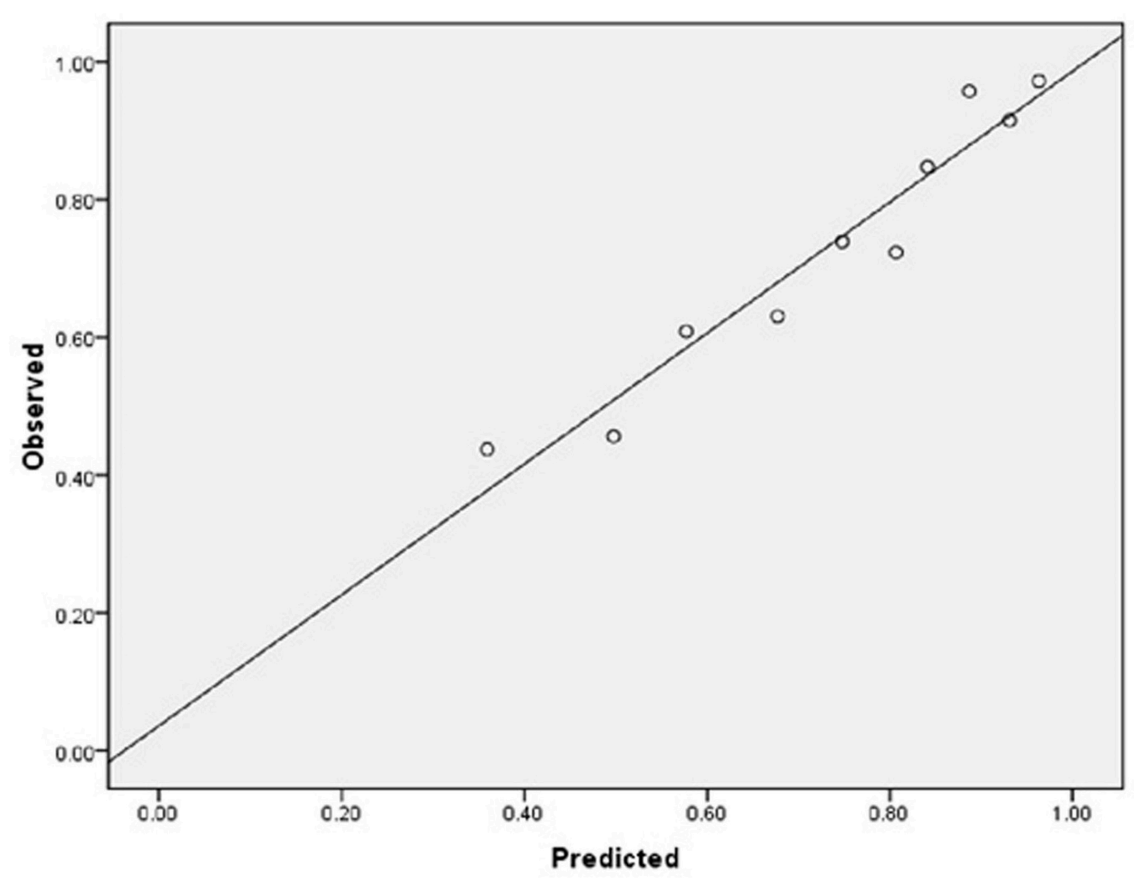

FIGURE 1 | The calibration plots (predicted vs. observed results).

TABLE 5 | The area under the curve of the scores of TIA.

\begin{tabular}{lcccc}
\hline Variable(s) & Area under the curve & $\boldsymbol{P}$ & \multicolumn{2}{c}{$\mathbf{9 5 \%}$ Confidence interval } \\
\hline Dawson & 0.681 & 0.001 & 0.629 & 0.732 \\
DOT & 0.728 & 0.001 & 0.680 & 0.776
\end{tabular}

predictors for the accurate diagnosis of TIA. Besides, for the first time, we have externally validated the DOT score as for a new tool of TIA in patients with TIA in China. Thirdly, we further confirmed the score of DOT could encompass the entire spectrum of TIA/stroke, which could be used as a mobile app or web-based calculator with higher accuracy.

In summary, we have externally validated the DOT score in patients with TIA in a Chinese population, and it was proved to be accurate as a diagnostic tool for TIA in China. The relative merits and clinical utility of the DOT score will warrant further prospective study in multiple centers with large samples.

\section{DATA AVAILABILITY}

The datasets for this manuscript are not publicly available because still recruit and in progress. Requests to access the datasets should be directed to JY,yuan_doctor@163.com.

\section{ETHICS STATEMENT}

Our work was approved by the Ethics Committee of Beijing Chaoyang Hospital, Capital Medical

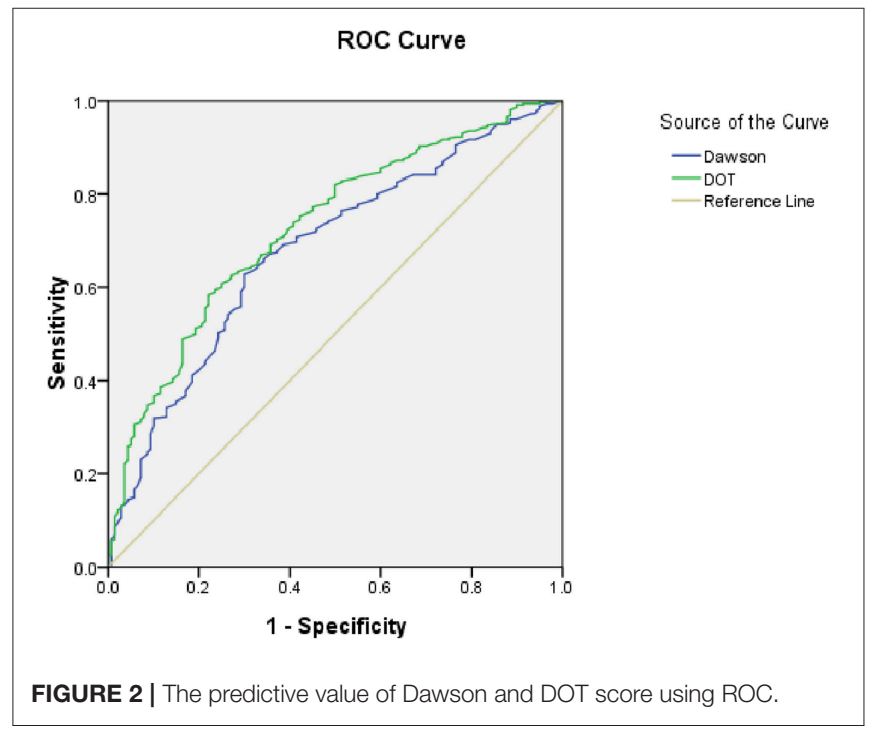

University. Written informed consent was obtained from all participants.

\section{AUTHOR CONTRIBUTIONS}

JY, ZJ, and YS examined, evaluated the patient. JY drafted and revised the manuscript. WH participated in the design of the case-report and helped to draft the manuscript. All authors read and approved the final manuscript. 


\section{FUNDING}

This work was supported by the National Natural Science Foundation of China (81301016) and the Beijing Municipal Administration of Hospitals Incubating Program (PX2019009).

\section{REFERENCES}

1. Donkor ES. Stroke in the $21^{\text {st }}$ century: a snapshot of the burden, epidemiology, and quality of life. Stroke Res Treat. (2018) 2018:3238165. doi: 10.1155/2018/3238165

2. Katan M, Luft A. Global burden of stroke. Semin Neurol. (2018) 38:208-11. doi: 10.1055/s-0038-1649503

3. Wang W, Jiang B, Sun H, Ru X, Sun D, Wang L, et al. Prevalence, incidence, and mortality of stroke in china: results from a nationwide population-based survey of 480687 adults. Circulation. (2017) 135:759-1. doi: 10.1161/circulationaha.116.025250

4. Khare S. Risk factors of transient ischemic attack: an overview. J Midlife Health. (2016) 7:2-7. doi: 10.4103/0976-7800.179166

5. Giles MF, Albers GW, Amarenco P, Arsava EM, Asimos AW, Ay H, et al. Early stroke risk and $\mathrm{ABCD} 2$ score performance in tissue- vs time-defined TIA: a multicenter study. Neurology. (2011) 77:1222-8. doi: 10.1212/WNL.0b013e3182309f91

6. Wardlaw J, Brazzelli M, Miranda H, Chappell F, McNamee P, Scotland G, et al. An assessment of the cost-effectiveness of magnetic resonance, including diffusion-weighted imaging, in patients with transient ischaemic attack and minor stroke: a systematic review, meta-analysis and economic evaluation. Health Technol Assess. (2014) 18:1-368. doi: 10.3310/hta18270

7. Crisostomo RA, Garcia MM, Tong DC. Detection of diffusionweighted MRI abnormalities in patients with transient ischemic attack: correlation with clinical characteristics. Stroke. (2003) 34:932-7. doi: 10.1161/01.STR.0000061496.00669.5E

8. Redgrave JN, Coutts SB, Schulz UG, Briley D, Rothwell PM. Systematic review of associations between the presence of acute ischemic lesions on diffusion-weighted imaging and clinical predictors of early stroke risk after transient ischemic attack. Stroke. (2007) 38:1482-88. doi: 10.1161/STROKEAHA.106.477380

9. Giles MF, Albers GW, Amarenco P, Arsava MM, Asimos A, Ay H, et al. Addition of brain infarction to the ABCD2 Score (ABCD2I): a collaborative analysis of unpublished data on 4574 patients. Stroke. (2010) 41:1907-3. doi: 10.1161/strokeaha.110.578971

10. Easton JD, Saver JL, Albers GW, Alberts MJ, Chaturvedi S, Feldmann E, et al. Definition and evaluation of transient ischemic attack: a scientific statement for healthcare professionals from the American Heart Association/American Stroke Association Stroke Council; Council on Cardiovascular Surgery and Anesthesia; Council on Cardiovascular Radiology and Intervention; Council on Cardiovascular Nursing; and the Interdisciplinary Council on Peripheral Vascular Disease. The American Academy of Neurology affirms the value of this statement as an educational tool for neurologists. Stroke. (2009) 40:2276-93. doi: 10.1161/strokeaha.108.192218

11. Giles MF, Rothwell PM. Risk of stroke early after transient ischaemic attack: a systematic review and meta-analysis. Lancet Neurol. (2007) 6:1063-72. doi: 10.1016/s1474-4422(07)70274-0

12. Coutts SB, Modi J, Patel SK, Demchuk AM, Goyal M, Hill MD. CT/CT angiography and MRI findings predict recurrent stroke after transient ischemic attack and minor stroke: results of the prospective CATCH study. Stroke. (2012) 43:1013-7. doi: 10.1161/strokeaha.111.637421

13. Hao Q, Tampi M, O’Donnell M, Foroutan F, Siemieniuk RA, Guyatt G. Clopidogrel plus aspirin versus aspirin alone for acute minor ischaemicstroke

\section{ACKNOWLEDGMENTS}

We thank Dr. Yicheng Xu, Weixue Wang, Shuang Wang, Zihan Yan, Yu Zhang for their great help for the data collection and analysis.

or high risk transient ischaemic attack: systematic review and meta-analysis. BMJ. (2018) 363:k5108. doi: 10.1136/bmj.k5108

14. Siket MS, Edlow J. Transient ischemic attack: an evidence-based update. Emerg Med Pract. (2013) 15:1-26.

15. Dawson J, Lamb KE, Quinn TJ, Lees KR, Horvers M, Verrijth MJ, et al. A recognition tool for transient ischaemic attack. QJM. (2009) 102:43-9. doi: $10.1093 /$ qjmed/hcn139

16. Lasserson DS, Mant D, Hobbs FD, Rothwell PM. Validation of a TIA recognition tool in primary and secondary care: implications for generalizability. Int J Stroke. (2015) 10:692-6. doi: 10.1111/ijs.12201

17. Dutta D. Diagnosis of TIA (DOT) score-design and validation of a new clinical diagnostic tool for transient ischaemic attack. BMC Neurol. (2016) 16:20. doi: 10.1186/s12883-016-0535-1

18. Whisnant JP, Basford JR, Bernstein EF, Cooper ES, Dyken ML, Easton JD, et al. Special report from the National Institute of Neurological Disorders and Stroke. Classification of cerebrovascular diseases III. Stroke. (1990) 21:637-76. doi: 10.1161/01.STR.21.4.637

19. Amort M, Fluri F, Schafer J, Weisskopf F, Katan M, Burow A, et al. Transient ischemic attack versus transient ischemic attack mimics: frequency, clinical characteristics and outcome. Cerebrovasc Dis. (2011) 32:57-64. doi: 10.1159/000327034

20. Sheehan OC, Merwick A, Kelly LA, Hannon N, Marnane M, Kyne L, et al. Diagnostic usefulness of the ABCD2 score to distinguish transient ischemic attack and minor ischemic stroke from noncerebrovascular events: the North Dublin TIA Study. Stroke. (2009) 40:3449-54. doi: 10.1161/strokeaha.109.557074

21. Mayer L, Ferrari J, Krebs S, Boehme C, Toell T, Matosevic B, et al. ABCD3I score and the risk of early or 3-month stroke recurrence in tissue- and time-based definitions of TIA and minor stroke. J Neurol. (2018) 265:530-4. doi: 10.1007/s00415-017-8720-8

22. Fitzpatrick T, Gocan S, Wang CQ, Hamel C, Bourgoin A, Dowlatshahi D, et al. How do neurologists diagnose transient ischemic attack: a systematic review. Int J Stroke. (2018) 14:115-24. doi: 10.1177/1747493018816430

23. Dutta D, Bowen E, Foy C. Four-year follow-up of transient ischemic attacks, strokes, and mimics: a retrospective transient ischemic attack clinic cohort study. Stroke. (2015) 46:1227-32. doi: 10.1161/strokeaha.114.008632

24. Giles MF, Rothwell PM. Substantial underestimation of the need for outpatient services for TIA and minor stroke. Age Ageing. (2007) 36:676-80. doi: 10.1093/ageing/afm088

25. Brazzelli M, Chappell FM, Miranda H, Shuler K, Dennis M, Sandercock PA, et al. Diffusion-weighted imaging and diagnosis of transient ischemic attack. Ann Neurol. (2014) 75:67-76. doi: 10.1002/ana.24026

Conflict of Interest Statement: The authors declare that the research was conducted in the absence of any commercial or financial relationships that could be construed as a potential conflict of interest.

Copyright (C) 2019 Yuan, Jia, Song and Hu. This is an open-access article distributed under the terms of the Creative Commons Attribution License (CC BY). The use, distribution or reproduction in other forums is permitted, provided the original author(s) and the copyright owner(s) are credited and that the original publication in this journal is cited, in accordance with accepted academic practice. No use, distribution or reproduction is permitted which does not comply with these terms. 